\title{
Wise City as an accessible city Directions of positive changes in Poland on the example of academic campus at the Silesian University of Technology in Gliwice
}

Katarzyna UJMA-WĄSOWICZ, Silesian University of Technology in Gliwice, Faculty of Architecture, Poland

\begin{abstract}
The development of any community is inextricably linked with the space in which a community functions. Neuroscience research reveal that the most negative emotions in social coexistence are triggered by exclusion, including inability to participate in public life due to architectural accessibility barriers. This means that without implementation of inclusive and pro-social space assumption, the negative, constantly functioning in numerous places state will not be changed. In Poland, a law on "ensuring accessibility for people with special needs" was enacted in July 2019, forcing administrators of public money to take measures to ensure that all facilities under their authority are adapted to the limitations and needs of users with varying degrees of disability. Due to this reason, among others, an action for widely understood accessibility was undertaken by the Silesian University of Technology. The realisation of this task overlaps with the idea of the "Wise City", which has recently been gaining increasing social acceptance and which aims to balance the influence of smart technology on urban planning and architecture through its coexistence with ecology and human potential. The aim of this paper is to present, on the example of a small public space in Gliwice belonging to the Silesian University of Technology, the planned and to some extent already implemented positive solutions not only in terms of eliminating architectural accessibility barriers but also in terms of implementing new, innovative on a Polish scale solutions for city accessibility such as navigation and information system for the blind compatible with tactile maps.
\end{abstract}

\section{Keywords}

Architectural accessibility, Wise City, Navigation and Information System for the Blind, Tactile Maps

\section{Introduction}

The development of any community is inextricably linked to the space in which it functions. This means that, on the one hand, the community shapes the space, and on the other, the space shapes the community. Among the many urban development trends that have gained acceptance and popularity in recent decades, such as the Just City, Smart City, Eco City, Green City, 15-minutes City or Wise City, the author believes that the latter should play a leading role, since its aim is to balance the (inevitable) impact of modern technologies on urban planning and architecture through its coexistence with ecology and human potential. 
Certainly in the coming future we should shape space by searching for its role rather than its shape. If the role of space is, among other things, to include all potential users in the participation of society, this will naturally fail without ensuring that the urban / architectural space is accessible to them.

It is not necessary to conduct strictly scientific research to observe that the most negative emotions in social coexistence are caused by exclusion. This means that without applying the assumption of inclusive and pro-social space in everyday life, we will not change this negative condition, which still exists in many places and eliminates different groups of users and status from social life.

In Poland, changes in this regard are moving, as it currently seems, in the right direction. In July 2019, a law on "ensuring accessibility for people with special needs" was passed, forcing the administrators of public money to take measures to ensure that all facilities under their authority are adapted to the limitations and needs of users with diverse disabilities (including the physically disabled, the blind and visually impaired, the deaf and hearing impaired, the autistic, the elderly, pregnant women and many others). Due to EU funding, universities have also been given the opportunity to introduce changes appropriate to accessibility for people with special needs in a range of fields, including space.

The aim of this paper is to present, on the example of a small public space in Gliwice belonging to the Silesian University of Technology, the planned and to some extent already implemented positive solutions not only in the area of eliminating architectural barriers, but also in the implementation of new, innovative solutions for urban accessibility in Poland.

\section{The concept of architectural accessibility - own research}

\subsection{Research methodology}

In order to gain a better insight into the area of studied issues, it is worth recalling the work of Marans and Stimson [Marans, Stimson 2011] covering the problem of Quality of Urban Life (QOUL). The authors, apart from analysing "classic" data in the field of objective indicators (data based on numbers, statistical data) and subjective indicators (resulting from users' assessments), also analysed behavioural indicators (observation of how space is used - how users function in it and use it). The last group of indicators included: use of public transport, visits to cultural institutions and participation in cultural events, visits to parks, participation in the activities of local authorities or mobility in the area of residence. The author's research has extended this list to include, among other things, mobility in the "in-between" buildings.

An important part of the search for optimal design of the built environment is also the question of architectural order as determining social functionality. Schumacher [Schumacher 2012] describes it in three dimensions: organisational, phenomenological and semiological. The organisational dimension encompasses the physical properties of space - it assumes that the effective use of the built environment depends on the ordering of users' activities in it and the way they move around. The phenomenological dimension relates to perceptual relationships - here the effective use of the built environment depends on the speed and ease with which the user gains an orientation and familiarity with a place. The last dimension: semiological, embraces semantic issues - effective use of the built environment is based on rapid and thorough understanding of this environment as a system of signs conveying their social meaning. I do not think anyone doubts that legibility and memorability of space and place gives a sense of security for every human being. In the case of people with disabilities this is particularly relevant.

When seeking to scientifically verify whether a given space meets the criteria for architectural accessibility, it is worth using two combined methods, i.e. a research walk and a method of qualitative research in architecture and urban planning called Post Occupancy Evaluation [8]. POE is a method for assessing the quality of the built environment during use with the participation of clients and users. This method of examining buildings and in-between them covers three basic issues: technical quality 
(technical condition, maintenance condition, standard, technical safety), functional quality (including organisational and ergonomic quality) and behavioural quality (the impact of the organisation of a place on /among other things/ behaviour, spatial orientation, safety, and the sense of aesthetics). In the group of behavioural issues, the sensory experience of space through smell, sound, touch, etc. is also addressed.

The research carried out by the Authors, although more in the nature of experience than of meticulous records so far, included all three questions, as it was this approach that allowed a complete picture to be obtained of the existing architectural and urban accessibility barriers in the space studied.

Currently, as part of the funding obtained in 2019 for the "Accessible University" project, a study entitled "Accessibility Standards of the Silesian University of Technology" is being finalised. To obtain authoritative results, a research method called Evidence-Based Design is employed, a concept derived from the knowledge-based medicine paradigm (Evidence-Based Medicine).The EBD approach was first defined by Hamilton and Watkins [2009] as follows: "the conscientious, explicit and judicious use of the best available knowledge from research and practice in making important decisions with an informed client as part of the work on any project". The authors of the concept list four levels of data-driven action: Peer Review, Unbiased Reporting, Hypothesis and Measurement, Critical Interpretation of Research. The comprehensive report in this matter is still an internal document of the Silesian University of Technology and will be published after the completion of the project, i.e. in 2022.

\subsection{Exclusion from architectural accessibility - where the problem lies}

The persistently existing architectural barriers for people with physical, sensory or intellectual disabilities are a key problem for the accessibility of public spaces. In this respect, urban audits, based as mentioned on the Evidence-Based Design research method, are the key word for the changes being undertaken. Most people, including designers, perceive architectural barriers through the prism of a given place: e.g. there is not a ramp or lift, parking space or adapted toilet. However, the lack of these architectural and urban elements is only a part of a much broader picture.

In order to comprehend the multiple dependencies which determine whether public spaces are accessible spaces for people with disabilities, it may be sufficient to examine a diagram called the Urban Circle of Life developed by the author . In order to benefit from public spaces in a meaningful way, it is necessary to reach them. The journey to the city, to the places of interest, commences from the place of residence of a person with disability, which in most cases is adapted to his special needs. For this person the first moment of encountering a barrier is leaving the flat, the next moment is leaving the house or block of flats, then getting to the car or to the public transport stop, getting to the destination place, parking the car or getting off at the desired bus stop, then walking from the car park or bus stop to the destination place. Finally, entering the building, moving around the building. The process of returning home is analogous. (Fig.1)

\section{¿ isocarp}




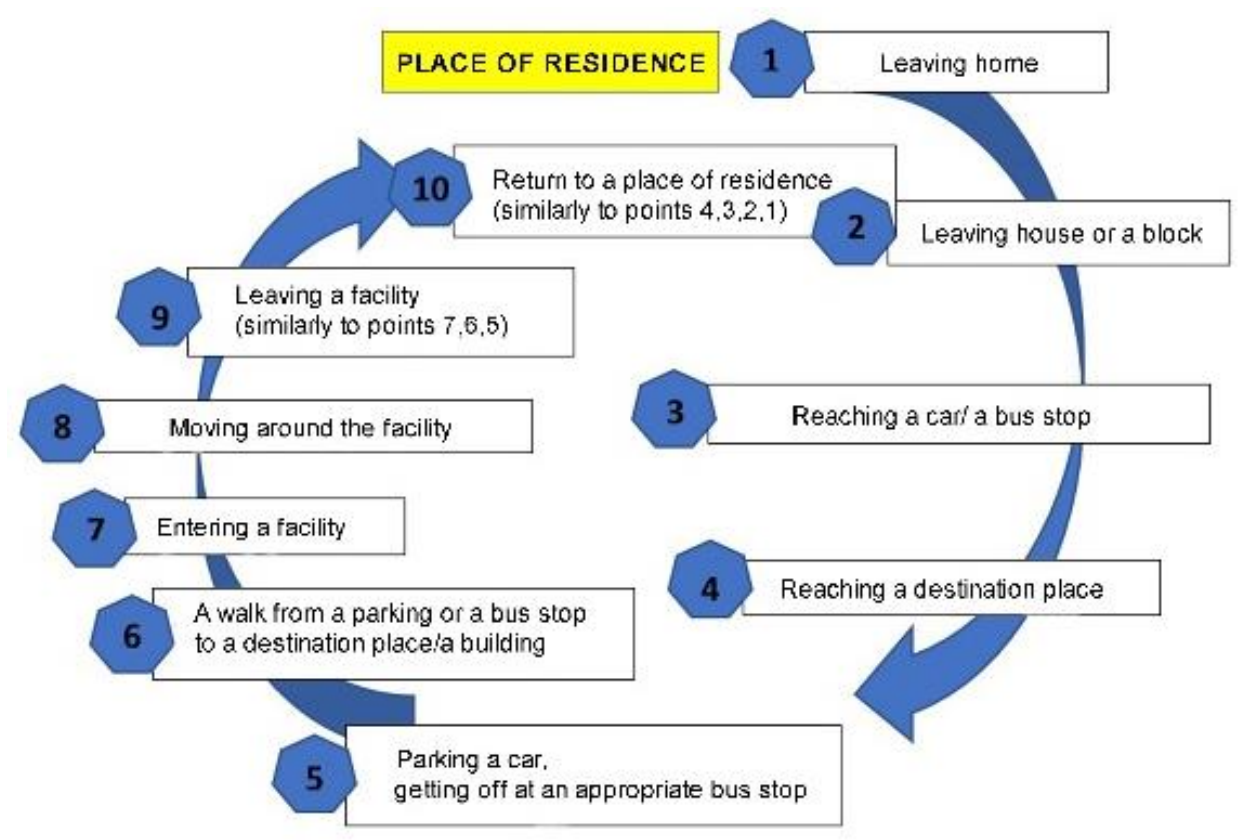

Figure 1. Urban circle of life (author: Ujma-Wąsowicz K.)

There is another important issue to be raised in this context. It is often the case that when designing an urban or architectural space, the designer thinks in the best of intentions about ensuring accessibility for all groups independently: for people in wheelchairs, for the blind, for the deaf, and others. However, it is important to realise that some seemingly most obvious concepts are not solutions for everyone: e.g. A lowered kerbstone for a person in a wheelchair is a great danger for a blind person ( they do not know at which moment they will find themselves in the street); modern and aesthetic touch panels in lifts are completely useless for blind people; repeated voice announcements in public transport are on the one hand crucial for orientation for people who do not know the route and for blind people, on the other hand they can be annoying and irritating, e.g. for the driver of a bus/tram, and many other incompatible ways of avoiding inconvenience. Therefore, in order to gain knowledge in this field, the audit should be carried out simultaneously with the participation of people with diverse disabilities, e.g. people in manual and electric wheelchairs, people who are blind from birth and go blind as adults, people who are deaf and have impaired hearing, etc. This is extremely necessary to remove spatial barriers in line with the principles and objectives of Universal Design.

\subsection{Wise City - the city of the future?}

As Francesco Schianchi states the concept of the city of wisdom corresponds to the Latin "civitas", which is a city of souls, of inhabitants, as opposed to "Urbis", a city of stones, of structures [https://www.matchup-project.eu/news/smart-city-and-wise-city/]. The wikipedia pages, on the other hand, read that Civitas was the religious and political association of the families of the tribe, while urbs was the place of reunion, the dwelling place and above all the sanctuary of this association. Thus, although Civitas and urbs, which we define as city, were not synonymous among the ancients, it is obvious that they should not exist without each other. Perhaps the author makes a rather risky thesis, but an analysis of the records of the Athenian Charter and the past years records the period of Modernism as one that, initiated in the 1930s by members of the CIAM, disrupted this seemingly obvious relationship.

As mentioned in the introduction there exist numerous (attractive) trends in the development of contemporary cities or cities of the future, such as cities of equality of people (Just City), cities supporting green and blue infrastructure (Eco City / Green City), polycentric cities, trying to eliminate car traffic as 
much as possible, and thus grey infrastructure (15-minutes City) and obviously cities saturated with intelligent technology (Smart City). While e.g. the first four ideas have the potential of a return to social integration and to nature, the last one seems in this context, although inevitable for the functioning of the " $Z$ " generation and younger, relatively unsafe. The term "Smart City" has grown in popularity over the last twenty years. Proponents of the digital revolution believe that communication technologies will radically transform cities, offering a wide range of new services that will simplify our daily lives. However, when you delve deeper, smart technology can lead not only to widespread surveillance, but also to the appropriation of human time and natural space. For smart technology to thrive, the collection of large data sets is essential. The risk is that their owners are/will be able not only to monitor what citizens do, but also to understand their will, which can influence collective behaviour.

In other words, for the modern city the adjective "smart" should be replaced by the word "wise", and the other concepts mentioned could easily be represented by the Wise City, an idea which aims to balance the inevitable influence of modern technology on architecture and urban planning through its symbiosis with ecology and human potential. The city of wisdom focuses on a quality of life in which no one feels excluded. [https://www.matchup-project.eu/news/smart-city-and-wise-city/]

\section{Accessibility of the campus of the Silesian University of Technology for people with dysfunctions}

\section{1. "Accessible University" - designated tasks in the area of architectural accessibility}

In 2019 the Silesian University of Technology has obtained from the European Social Fund (European Union) from the Operational Programme Knowledge-Education-Development (PO WER), the opportunity to implement the task referred to in brief as "Accessible University". Funding for the project allows for the introduction, mainly for disabled and other limited students and employees of the University of Technology, of lasting changes in terms of ensuring widely understood architectural, communication and information and digital accessibility. The title of the research project to be executed over three years (from 1 January 2020 to 31 December 2022) is: "The Silesian University of Technology - a university aware of needs and equalising life chances". It should be added that the Silesian University of Technology has been realising the accessibility programme for many years, but its previous activities were based on individual initiatives, grassroots character, which resulted in only a random improvement of studying and working conditions. Conducting activities within the scope of this project permits the theme to be put into effect at various levels, including primarily at the material level (removal of architectural barriers) and training level (extensive education among employees and students).

The key body established within the project is a unit consisting of a Team of Experts / Advisors (including students and doctoral students with disabilities), whose task is to harmoniously organise all possible actions, guaranteeing successive improvement of studying and working conditions for persons with special needs. Under its auspices, for example, activities related to the development of "accessibility standards" for the Silesian University of Technology are being finalised, implementing not only the principles of universal design, but also (which is not very often included in "standards" developed for various cities in Poland) the principles of ergonomic design.

As part of the project, an extremely significant task will be the establishment in the near future of the socalled "Accessibility Laboratory" located in a small urban space which is part of the academic town of the Silesian University of Technology in Gliwice and in a designated room in the building next to the Office for Persons with Disabilities at SUT. The aim of the activities of the Laboratory will be to enable interdisciplinary research on the problems of human functioning in accordance with the principles of universal design with the use of smart technologies, and to test the implemented solutions. The 
"Accessibility Laboratory" will not only be a research field; it will also serve didactic and analytical purposes for students, graduates and employees of the Silesian University of Technology.

\subsection{Navigation and Information System for the Blind - electronic markers}

One of the - not only desirable, but also seemingly more interesting - solutions implemented by the Silesian University of Technology within the framework of the "Accessible university" is modern thinking about facilitating spatial orientation for people with disabilities, in particular visual impairments. The issue of safety of blind and visually impaired persons is very neglected in Poland, in the public space, and the applied solutions are selective and ineffective [http://totupoint.pl/strona.php?nazwa=geneza]. On the one hand, the world is overcrowded with various messages, on the other hand, there is a problem with obtaining and delivering information for this group of users about a particular place they would like to visit at a particular time. The point is that it should be provided for them in a simple form, easy to comprehend, but at the same time not intrusive, so that they can get acquainted with it before they leave home, so that it is not only visual, but also in voice form.

The founders of the Warsaw-based company "PIRS Creative Lab", in particular Jan Szuster (a blind person who lost his sight as an adult), came to the conclusion that contemporary technological progress creates opportunities to solve the issue of access to information about a place in a systemic way: by using a single technology, a unified user interface and commonly available mobile devices. Therefore, they have planned and executed a number of projects based not only on a correct analysis of the issue, where the identification of needs is the result of their own experience and knowledge of the needs of others in this environment, but also on their professional knowledge in the field of electronic and IT projects. [http://totupoint.pl/strona.php?nazwa=lista_znacznikow_totupoint]

The innovation of their system is based on an infrastructure made of electronic markers and personal mobile devices, which may be modern smartphones or tablets. Accessibility for visually impaired people is based on the fact that these mobile devices are inherently sound-based and therefore accessible without sight. In addition, for this group of users a module has been developed for installation on the handle of a white cane where vibration mechanisms facilitate operation of the system also for people with hearing problems.

These markers are electronic devices made in the form of small elements (small boxes with dimensions of approximately $6 \mathrm{~cm} \times 12 \mathrm{~cm}$ ) and designed to be placed both indoors and outdoors. They have an autonomous energy source optimised to last not less than 3 years. The high tightness class and the possibility of operating in a wide range of temperatures $\left(-30^{\circ} \mathrm{C}\right.$ to $\left.+80^{\circ} \mathrm{C}\right)$ enable their placement in any chosen location with almost unlimited possibilities.

The primary role of markers is to make available the information stored in them. In addition, however, they can be equipped with various sensors (e.g. thermometer, hazardous gas detector, etc.) or with signalling and alarm systems if they perform warning functions. Installation and exploitation of the markers is extremely simple, which serves the development and dissemination of the system - an essential element of the PIRS company concept. Furthermore, the markers do not have any connectors for external interfaces, as they communicate via the BLE (Bluetooth Low Energy) radio interface, which is currently widely deployed mainly in mobile devices.

For example, when a visually impaired person is seeking a specific address, the application enables him to find it similarly to normal navigation systems, however, the final moment of locating is provided by a directed voice (as if someone standing at the door was calling him) saying - here I am! Here is the place you are looking for! (Fig. 2) 


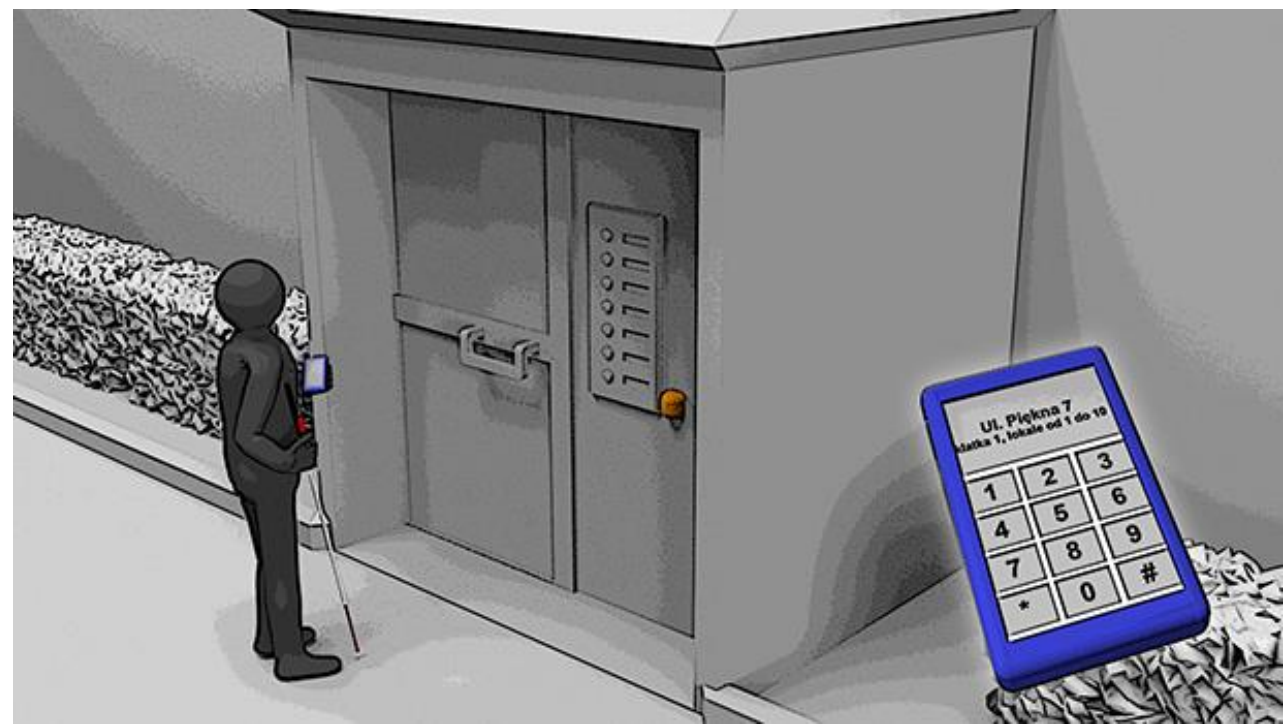

Figure 2. Electronic marker (TOTUPOINT) helping to find the target address (source: http://www.totupoint.pl/strona.php?nazwa=galeria)

In order to realise the idea of making the campus of the Silesian University of Technology accessible to people with disabilities, in particular visual impairments, locations of points belonging to the navigation and information system, which has been described above, have been planned. Within the framework of the "Accessible university" project 200 electronic markers will be installed in characteristic places in university campuses in Gliwice, Katowice and Zabrze. The markers will be located:

- Above main entranses to buildings accessible to academic community,

— In selected buildings: at the gatehouse (inforamtion desk),

above the doors of toiletes,

near the main staircase and / or the lift.

On the map below (Fig.3), depicting the campus of Silesian University of Technology in Gliwice, there are shown, in order from 1 to 53, all the places where the markers are to be installed outdoors: the green colour " 1 " is where the campus' typhflological map will be placed, further locations are the entrance areas to the university's teaching and administrative facilities, library, dormitories, clinics, etc. Marker " $A$ " indicates the location of a bus stop, where potential markers can only be placed by the city, as the owner of the place.

\section{THE CAMPUS OF SILESIAN UNIVERSITY OF TECHNOLOGY IN GLIWICE}

Places of electronic markers location for people with disabilities, particularly for the blind MAP KEY A- bus stop

1. Typhlo-map of the campus

2. Entrance to the Rectorate

3. Entrance to the square to Faculty of Mining

4. Entrance to the Faculty of Mining

5. Entrance to the Faculty of Electrical Engineering 1

6. Entrance to the Faculty of Electrical Engineering 2

7. Entrance to the Faculty of Electrical Engineering 3

8. Entrance to the Office for People with Disabilities

9. Entrance to the Project Management Office

10. Entrance to the Centre of Innovation and Technology Transfer

11. Entrance to the Faculty of Chemistry 1

12. Entrance to the Faculty of Chemistry 2

13. Entrance to the Silesian University Club for the

31. Entrance to the "Sezam" Dormitory

32. Entrance to the "Karolinka" Dormitory

33. Entrance to the "Karlik 1" Dormitory

34. Entrance to the "Karlik 2" Dormitory

35. Entrance to Orlik

36. Entrance to the "Mrowisko" + Student Club

37. Entrance to the "Solaris" Dormitory

38. Entrance to the Assistant's House

39. Entrance to the Library

40. Entrance to the Faculty of Mathematics

41. Entrance to the Faculty of Mechanical Engineering and Technology

42. Entrance to the Education and Congress Centre

\section{S ISOCARP}




\section{Employee}

14. Entrance to the Faculty of Construction 15. Entrance to the Faculty of Architecture 16. Entrance to the New Hall

17. Entrance to the Laboratory

18. Entrance to the Faculty of Automation, Electronics and Information Technology

19. Entrance to the Academic Out-Patient Clinic

20. Entrance to the Information Technology Centre

21. Entrance to the OSiR Hall 1

22. Entrance to the OSiR Hall 2

23. Entrance to the Academic Canteen

24. Entrance to the "Rzepicha" Dormitory

25. Entrance to the "Piast" Dormitory

26. Entrance to the "Ziemowit" Dormitory

27. Entrance to the "Barbara" Dormitory

28. Entrance to the "Ondraszek"Dormitory

29. Entrance to the "Strzecha" Dormitory

30. Entrance to the "Elektron" Dormitory
43. Entrance to the Science and Techn. Park 1

44. Entrance to the Science and Techn. Park 2

45. Entrance to the Faculty of Energy and Environmental Engineering 1

46. Entrance to the Faculty of Energy and Environmental Engineering 2

47. Entrance to the Faculty of Energy and Environmental Engineering $3+$ Student Career Office

48. Entrance to the Faculty of Energy and Environmental Engineering 4

49. Entrance to the Faculty of Energy and Environmental Engineering $5+$ Sports Hall

50. Entrance to the Scientific and Didactic Centre of New Technology

51. Entrance to the " $X$ " + Comprehensive School 52. Entrance to the Faculty of "Red" Chemistry 53. Entrance to the Faculty of "Grey" Chemistry
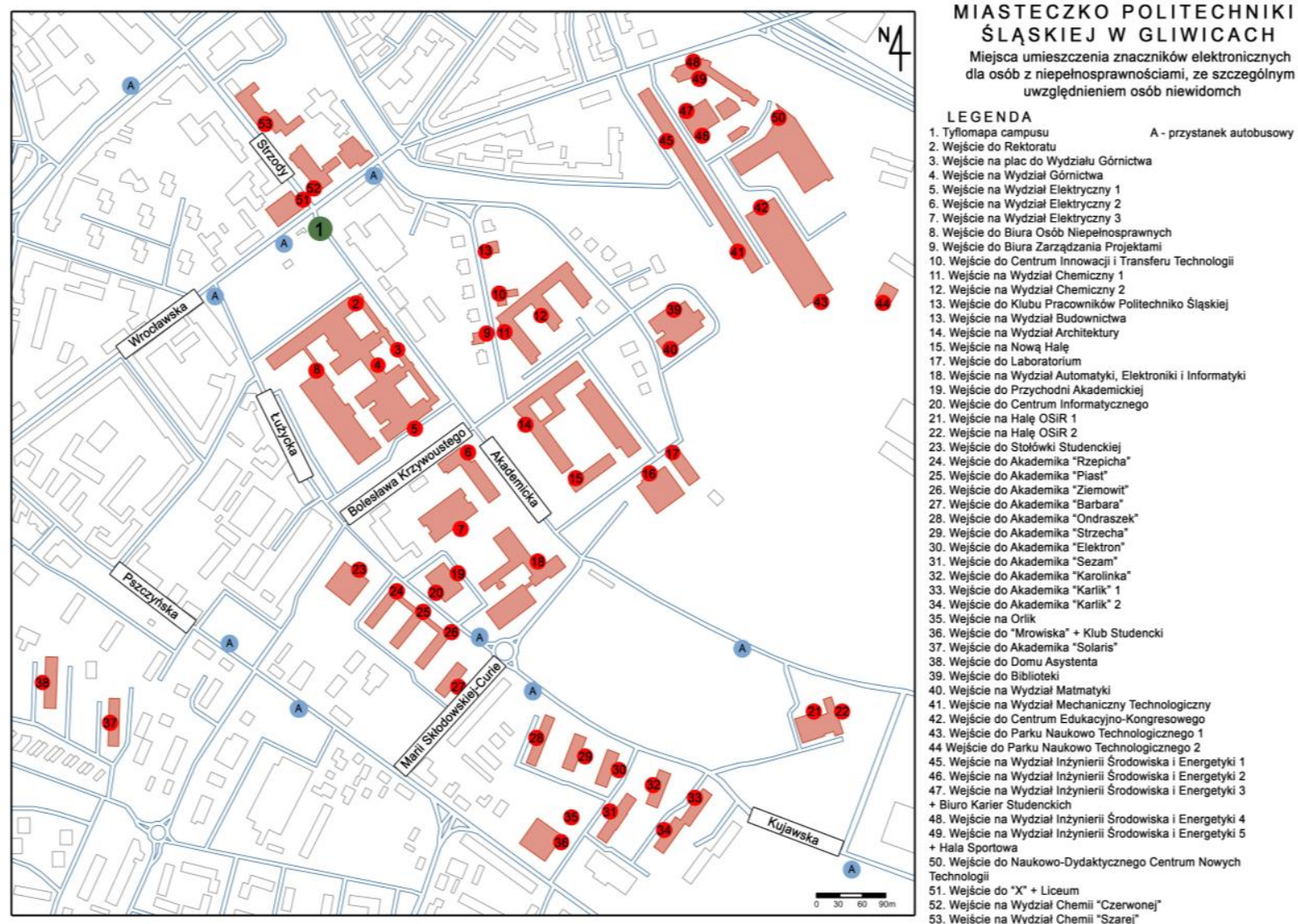

Figure 3. Map showing locations of points belonging to the navigation and information system on the campus of the Silesian University of Technology in Gliwice (source: own elaboration)

\section{Summary}

The idea of the Wise City seems to be an indispensable direction for the development of 21st century cities. We will not avoid the interference of modern technology into the life of an individual, let us hope 
we will avoid its interference into social life. This can be prevented if citizens co-design urban space according to their needs. This path will also lead to a reduction in social exclusion and loneliness, making cities more suitable for children, the elderly and the disabled. And this is something that technology alone cannot achieve without citizen participation [Inteligentne miasto i mądre miasto - MatchUp MatchUp (matchup-project.eu)] The idea of the Wise City also fits perfectly with the philosophy of universal design. Universal design (and building) is a range of environmental accommodations according to the needs and limitations of people with permanent or temporary disabilities. It is also the result of interdisciplinary research, e.g. in ergonomics, sociology, psychology or cognitive science, constantly providing new knowledge in the field of architectural accessibility.

One of the extremely interesting solutions which bring new quality to everyday life for people with dysfunctions, especially visual impairment, is the innovative, on the one hand, and simple and intuitive, on the other, navigation and information system described above. The nationwide "Accessible University" project conducted at the Silesian University of Technology and co-financed by the European Union will allow the implementation of this very effective method of spatial orientation.

\section{References}

Aronson E. (2012): Psychologia społeczna. Wydawnictwo Zysk i S-ka, Poznań

Hamilton D.K., Watkins D.H. (2009): Evidence-based design for multiple building types. John Wiley \& Sons

Marans R.W., Stimson R.J. (2011) 'An overview of quality of urban life', Investigating quality of urban life. Springer

Marshall G. (eds.) (2008): Słownik socjologii i nauk społecznych. Wydawnictwo Naukowe PWN

Konwencja o prawach osób z niepełnosprawnościami. Dz. U. 2012 poz. 1169 z 25.10.2012

Preiser W., Rabinowitz H., White E. (1988) Post Occupancy Evaluation. Van Nostrand Reinhold, New York

Schumacher P. (2012): The Autopoiesis of Architecture. Volume II: A New Agenda for Architecture. John Wiley \& Sons

Ustawa z dnia 19 lipca 2019 r. o zapewnianiu dostępności osobom ze szczególnymi potrzebami (Dz. U. 2019 poz. 1696)

The possibilities for success of the sustainable communities approach and its implementation. Volume I: Study. Policy Department, Structural and Cohesion Policies of European Parlament; March 2007

https://www.matchup-project.eu/news/smart-city-and-wise-city (access: 15.09.2021)

http://totupoint.pl/strona.php?nazwa=geneza (access: 15.09.2021)

http://totupoint.pl/strona.php?nazwa=lista_znacznikow_totupoint (access: 15.09.2021)

Inteligentne miasto i mądre miasto - MatchUp - MatchUp (matchup-project.eu) (access: 15.09.2021)

\section{¿ isocarp}

